$\angle$ Research Square
Preprints are preliminary reports that have not undergone peer review.

They should not be considered conclusive, used to inform clinical practice, or referenced by the media as validated information.

\title{
Alienated and unsafe: Life through the Covid-19 lockdown for vulnerable young people (aged 11-24 years) as revealed in web-based therapeutic sessions with mental health professionals
}

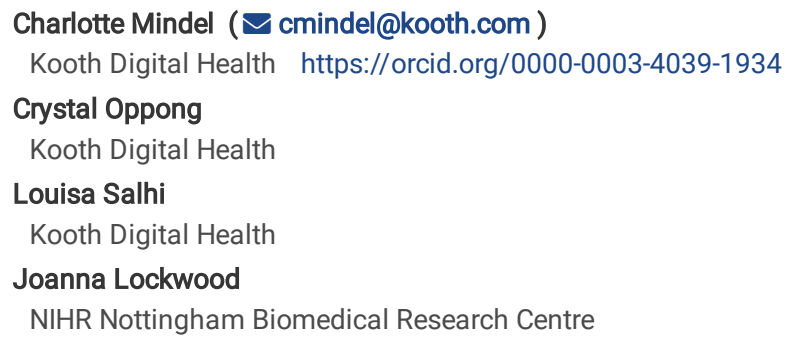

Research article

Keywords: Digital Mental Health, Adolescents, Young people, Mental Health

Posted Date: August 19th, 2021

DOl: https://doi.org/10.21203/rs.3.rs-819675/v1

License: (c) (7) This work is licensed under a Creative Commons Attribution 4.0 International License. Read Full License 


\section{Abstract \\ Background}

The Covid-19 pandemic and subsequent lockdowns have detrimentally and disproportionately affected young people, with those who are considered vulnerable due to their experiences or life circumstances disadvantaged further still. In this study, we seek to understand the experiences of vulnerable young people accessing web-based therapeutic support during the pandemic and early lockdown, as revealed through the observations of mental health professionals.

\section{Methods}

Four focus groups with twelve web-based mental health professionals from the service Kooth were conducted on Zoom, and data analysed using thematic analysis. Participatory workshops with young people with diverse experiences supplemented the study approach and design and involved young people in the co-design of the focus group topic guide and the interpretation and validation of analysis.

\section{Results}

Four main themes and additional sub-themes were identified relating to the experiences of vulnerable young people on a web-based mental health platform. These were Escalation of risk, The Experience and Consequence of Loss, Feeling Supported and Empowered, and Feeling Separate and Isolated.

\section{Conclusions}

Findings broadly reflect early data that suggests that those with existing vulnerability face increased risk of poor outcomes through the pandemic and the restrictions of lockdown, but evidence is also provided of positive outcomes from lockdown and its function as a catalyst for change. Results reinforce that focused support for vulnerable young people is a priority as we emerge from lockdown and points to support and protective factors of relevance to online and offline support provision. The study uniquely contributes qualitative insight from web-based mental health professionals who have provided continuity of care to vulnerable youth from pre-pandemic and during lockdown and are therefore well-positioned to understand the impact of lockdown on the lives of service users. The robust youth-based participatory design is an additional study strength.

\section{Background}

Increasing evidence is revealing the economic, social and psychological ways in which the Covid-19 pandemic, and subsequent national lockdowns, have detrimentally and disproportionately impacted the lives of children and young people (1-3). Such factors are likely to contribute to the growing mental health crisis in youth (2), predicted even prior to the pandemic to be a leading issue facing children and young people by 2040 (4). Economically, those under 25 years have faced poorer labour market outcomes and greater loss of earnings and working restrictions than older employed adults during the pandemic $(1,5)$. Financial hardship and employment instability has particularly affected those from lower socioeconomic circumstances, and minority ethnic backgrounds (2, 6). The closure of education settings and wider loss of extra-curricular provision and play spaces in the community have negatively impacted educational, physical and social opportunities, and support networks for young people $(7,8)$, which is likely to have an immediate and long-term impact. Pooled estimates from a systematic review of global evidence indicate that $79.4 \%$ of children revealed a worsening of their behaviour or psychological state as a result of the pandemic, including increased levels of anxiety, depression and irritability (9). In the UK, young people have reported increased boredom and frustration over the pandemic, with more than half young people surveyed reporting feeling lonely during the first lockdown (10-12). Taken together, the potential costs to young people of the pandemic and lockdown are stark. Those with heightened vulnerability prior to the pandemic, due to their experiences, life circumstances, or existing mental health difficulties, are likely to share an unequal burden $(7,13)$.

Young people with heightened vulnerability, such as those at elevated risk for adverse childhood experiences (ACEs) may experience increased risk during times of unprecedented change, such as during the Covid-19 pandemic (14). ACEs are defined by ten experiences including physical, emotional, and psychological abuse, as well as having family members with mental health problems (15). These experiences put children and young people at risk of physical, emotional or psychological harm as well as increasing their susceptibility to poorer outcomes in life (16-18). In comparison to young people with no ACEs, young people who have faced four or more ACEs are four times more likely to have low levels of wellbeing and life satisfaction, seven times more likely to have been involved in violence, and are more likely to binge drink or have poor diets (19). Adverse experiences such as domestic violence increased with the introduction of lockdown restrictions in the UK in March 2020 (20) and increased time locked down has exacerbated risks for vulnerable young people in unsafe and insecure home environments $(6,21)$. For children who are already experiencing abuse or neglect by household members, confinement at home has meant prolonged exposure to potential harm (18) alongside reduced opportunities to escape or disclose e.g. at school (22). When faced with adversity, individuals may adopt both adaptive and maladaptive coping mechanisms in order to deal with their situation (23), with the latter increasing the risk of selfharm or other harmful behaviours $(24,25)$. Of note, not just experiencing adversity (such as physical or psychological abuse) but worrying about adversity over the first 45 weeks of the Covid-19 was associated with increased risk of self-harm thoughts and behaviours in those aged 18+ (26).

Typically, young people who are in situations where they could be exposed to multiple ACEs are known to services, however, findings from preliminary research show that with services becoming over-stretched as a consequence of the pandemic $(7,27)$, individuals previously accessing support experienced delays in both physical and mental health care (28), with some facing the removal of support completely, for example, those being visited by welfare services due to risk Loading [MathJax]/jax/output/CommonHTML/jax.js ind that $26 \%$ of young people who received support leading up to the pandemic are no longer able to access the 
same level of support due to uncertainty of availability or lack of privacy for remote interaction, leading to increased levels of anxiety. In response, many services have rapidly adapted to deliver non-face-to-face support, such as telephone counselling. Such models are not new and can offer privacy and control to the young person (31), but may not be a viable alternative arrangement for all young people.

Established web-based therapeutic services, such as online counselling, have been in a privileged position since the pandemic started, able to continue to provide their existing model of direct counselling and wellbeing support without need for adaptation. Kooth plc, one of the UK's leading digital mental health providers, is one such web-based therapy service that has provided a consistent offer to young people aged 11 to 25 years. Kooth's text-based approach to synchronous counselling or support allows the user to access the service to receive support on any internet-connected device, providing an anonymous means of communication and agency (32). Anonymity at the point of access is a cornerstone of Kooth's approach providing a viable option for those who face cultural or societal stigma related to mental health help-seeking, or are not comfortable disclosing their difficulties in a face-to-face setting. The universal approach of Kooth enables support for those who might otherwise not be seen by services due to not meeting the strict threshold or criteria necessary to access Child and Adolescent Mental Health Services (CAMHS) (33). Kooth has reported a $42 \%$ increase in usage by service users aged between 11 and 25 years since the start of the pandemic. In addition, a higher proportion of those accessing Kooth presented with 'severe' distress on a standardised mental health assessment between April and December 2020 in concordance with the national lockdown periods in the UK (34). The changes recorded in data collected by Kooth, and data collected nationally (20) reflect an overall increase in distress for children and young people. While existing studies have provided rapid insight into the impact of COVID-19 and lockdown, there remains a lack of qualitative insight into the experiences and understanding of lockdown for the most vulnerable children and young people.

The current study

The aim of this study is to understand how lockdown has been experienced by young people with heightened vulnerability (due to prior experiences and life circumstances) who have sought mental health support via Kooth. Specifically, the study aims to assess the experiences of young service-users meeting a predetermined definition of vulnerability (see below) who have been engaging with the service via structured counselling or ongoing support sessions with a Kooth practitioner prior to the pandemic and during lockdown. Access to young people's experiences is sought indirectly through text-based dialogue with practitioners who are well placed to reflect broadly on the experiences of the individuals they work with. This mediated approach has pragmatic and ethical merit and does not add research burden to a vulnerable group at a time of significant disruption. In addition, practitioners are positioned to share insight into patterns of experiences revealed across a consistent model of therapeutic engagement from before and during lockdown. Nonetheless, given that vulnerable groups including mental health service users are often excluded from meaningful engagement with research $(35,36)$ we drew on a robust multi-phase Patient and Public Involvement (PPI) participatory approach working with a diverse group of young people to guide the research approach, design and analysis.

Vulnerability in this study has been defined based on accepted terminology in the academic literature, discussed and agreed in partnership at the outset of the study with our PPI group. The ACEs ten-item list (see supplementary material) has been critiqued for lacking the inclusivity of all experiences that may lead to poorer life outcomes (15). This critique was endorsed by our PPI group. Accordingly, our definition was expanded to also include: economic disadvantage; discrimination based on religion, ethnicity or gender; status as a refugee or asylum seeker, and those experiencing peer victimisation.

\section{Methods}

Study design

The study employed a qualitative design which used online focus groups with practitioners. The aim was to capture professional and mediated interpretation of service-user experiences from engaging with vulnerable young people within a caseload. Focus groups provided a platform for facilitated discussion and rich insight. Thematic Analysis within an experiential inductive-deductive framework was an appropriate method for identifying and analysing patterns in the data $(37,38)$. Qualitative findings are reported in line with good practice guidelines set by the Consolidated Criteria for Reporting Qualitative Research (39).

The study was reviewed and approved by the University of Exeter Ethics Committee [eCLESPsy001970].

Researcher Positionality

Three of the four researchers were based at Kooth during their involvement in the study, committed to building the evidence base for, and promotion of digital mental health services. Originating from a range of academic backgrounds including neuropsychology, sociology, mental health, and psychology, the four researchers bring a variety of viewpoints, knowledge bases and experiences to this research and particularly the interpretation of the findings. Marginalised and less reached groups are areas of focus that are of particular interest to two of the researchers due to either their own experiences with mental health services or their cultural identity as a black woman, recognising the importance of exploring the nuance of experience for those who may have different experiences to 'the norm'. To reduce the possible bias introduced as a result of these lived experiences, special attention was paid to developing neutral questions for the focus groups so as to not make them leading or assuming any particular experience.

For the two researchers who conducted the focus groups, recognising their status as 'insiders', working for the same organisation as participants and the potential bias introduced through having a shared investment in adolescent wellbeing, it was important that the practitioners were supported in feeling like the experts in the room and that no prior assumptions were made about the outcomes of the focus groups. This consideration helped in mitigating any assumed knowledge by the researcher about the 'expected' experiences of vulnerable young people, both during data collection and analysis. Researchers three and four were newly appointed to Kooth, and an outsider of the organisation, respectively. While there was still a focus on digital mental health and adolescent health within the professional capacity of these researchers, the reduced knowledge of Kooth's inner working supported a critical, fresh and reflexive approach to the thematic analysis which was undertaken and developed by all four researchers.

Loading [MathJax]/jax/output/CommonHTML/jax.js 
The study design and analysis were guided by co-design workshops with young people facilitated by Leaders Unlocked who were commissioned by Kooth to drive the involvement of young people in this study. Three participatory co-design workshops were held with 11 members of Leaders Unlocked to inform the conceptualisation, design, focus group topic guide (workshop 1), analysis/interpretation of results (workshop 2) and dissemination plans (workshop 3). Workshops were facilitated by Leaders Unlocked, they took place between October 2020 and January 2021 via Zoom and consisted of five females and six males aged 16 and 25 years, from a range of ethnic backgrounds (Asian 18\%, Black 9\%, Mixed ethnicity 18\%, and White 55\%).

Workshop 1 explored notions of vulnerability, priorities for understanding lockdown from the perspective of vulnerable young people, and the scope and acceptability of the topic guide. Important outcomes included the necessity to clearly understand and define 'vulnerability' and identify additional and potentially underrepresented groups which meet these criteria (e.g. asylum seekers), and the importance of reflecting youth behaviour during lockdown in relation to coping mechanisms. Workshop 2 was conducted with the same group of young people halfway through the focus group stage and served to review initial findings, support the ongoing analysis of data, and inform the approach to data collection and analysis in the remaining focus groups (see Fig. 1; workshop agenda in supplementary materials). Workshop 3 saw the group bring their examples of accessible research to a discussion about how research can be translated into accessible media for consumption and use by young people as well as adults.

Participants and recruitment

The study ran between November 2020 and January 2021. Twelve practitioners (age range 26-66 years; 11 female and 1 male; $83 \%$ White British, 17\% White Other) took part. All were employed at Kooth as qualified Counsellors or Emotional Wellbeing Practitioners. Kooth counsellors have a minimum of two to three years prior experience working with young people in face-to-face or online settings. Years of experience working at Kooth ranged from 1-5 years. Despite Kooth being an early intervention service, service users often present risk, which include young people who meet the criteria of our vulnerable population. Kooth users tend to sit within different theoretical pathways related to how they use the service. These consist of brief intermittent interventions which are drop-in sessions with any practitioner who is available at the time, structured interventions in which the user engages with a series of scheduled sessions with a consistent practitioner, and on-going support for those who have more complex situations and require support either to engage on Kooth or with other services available to them. The service users whose experiences were being discussed in this study were engaged in either structured or on-going support (40).

Opportunity and purposive sampling methods were used to recruit participants. In order to draw on experiences specific to the Covid-19 pandemic, the inclusion criteria stipulated that practitioners needed to have i) been employed with Kooth prior to February 2020 i.e. before the first UK Covid-19 lockdown; and ii) have worked with a minimum of one service user between March and October 2020 who they identified as meeting the agreed vulnerability criteria prior to the start of the first lockdown. Study advertisements were distributed through internal communication channels in Kooth (e.g. email/Slack) to all practitioners who were eligible based on their start date at Kooth. In addition, senior practitioners who manage teams of Kooth practitioners were provided with study information to share with members of their team who they identified as meeting the criteria as a secondary means of recruitment.

Procedure and materials

Practitioners were invited to read the study information sheet and provided informed consent before being invited to take part in one of four online focus groups. Sessions lasted 90-minutes and were facilitated by two researchers (CM, CO) via Zoom video conferencing software. Each group comprised three practitioners and allocation was determined on the basis of availability and broad range of experience. Given the specific experience of participants as Kooth practitioners and breadth of experience in their profession, twelve participants in total were deemed to provide sufficient information power for the analysis (41). Focus groups were audio recorded and transcribed verbatim, with additional notes recorded in the session to demarcate key points of agreement or contention. Practitioners were offered an overtime contribution for their participation as reimbursement for their time and were encouraged to speak to peers and engage with support if they found participation in the study and the issues raised to be distressing. This was particularly important to reinforce given the unsettling and emotionally demanding nature of an ongoing pandemic.

Focus groups followed a semi-structured topic guide which broadly explored five areas: (1) The physical elements of lockdown, such as the impact of closure or change of interaction with physical institutions such as schools. (2) The emotional experience of lockdown, exploring presenting issues that were considered unique to the circumstances of the pandemic by the practitioner. (3) Coping mechanisms adopted by young people due to their pandemic experiences. (4) General experiences or tropes unique to the pandemic circumstances. (5) Long term changes referring to any shift in experiences for young people as restrictions eased and tightened throughout the pandemic. Topics were informed by anecdotal insights from practitioners and service delivery staff at Kooth, research and media reporting, and participatory discussions with Leaders Unlocked. Practitioners were encouraged to share general insights or discuss cases in a general way rather than providing specific details of individual cases in order to adhere to the ethical frameworks of counselling and protect the confidentiality of the clients. As Kooth is an anonymous service, where personal identifiable information is only shared at the discretion of the user during a safeguarding interaction, the risk of practitioners sharing personally identifiable user information with the researchers was reduced. Any case details that could be identifiable were redacted prior to analysis of the transcripts.

\section{Data analysis}

Data were analysed following principles of Thematic Analysis $(37,38)$. Initially, two researchers $(\mathrm{CM}, \mathrm{CO})$ familiarised themselves with the data by reading and re-reading the transcripts, before coding. The codes were transferred into an online whiteboard tool, Miro, which facilitated the visual organisation and moving of data and supported the clustering of codes, generation of initial themes and creation of thematic maps. Themes were developed and reviewed according to deductive (based on prior research) and inductive processes. Midway through analysis, identified patterns and relationships in the data were presented for dicnuccinn with ununn nonnlo within tho cagond participatory workshop. The discursive process involving multiple researchers and our PPI group brought rigor Loading [MathJax]/jax/output/CommonHTML/jax.js 
and cohesion to the analysis and ensured that interpretations could be challenged and validated by young people. A final step involved refining, defining and naming the major themes and sub-themes, involving all four researchers (CM, CO, LS, JL) in a process of iterative, critical, and reflexive discussion.

\section{Results}

As shown in Table 1, four major themes were identified: (1) Escalation of risk (2) The experience and consequence of loss (3) Feeling supported and empowered (4) Feeling separate and isolated. All names used for practitioners throughout the results are pseudonyms.

Table 1

Major Themes, Sub-themes identified through analysis

\begin{tabular}{|c|c|c|}
\hline Major Theme & Definition & Sub-theme \\
\hline \multirow[t]{3}{*}{ Escalation of risk } & $\begin{array}{l}\text { Risk is intensified through changing external factors and } \\
\text { maladaptive coping }\end{array}$ & $\begin{array}{l}\text { 1. Abuse and harmful changes within the } \\
\text { home }\end{array}$ \\
\hline & & 2. Adopting maladaptive coping mechanisms \\
\hline & & 3. Missed opportunities for care \\
\hline \multirow[t]{3}{*}{$\begin{array}{l}\text { The experience and consequence } \\
\text { of loss }\end{array}$} & $\begin{array}{l}\text { Exploring the pervasive notion of loss and how it impacted young } \\
\text { people }\end{array}$ & $\begin{array}{l}\text { 1. The consequence of being physically } \\
\text { disconnected }\end{array}$ \\
\hline & & 2. Stuck in stasis \\
\hline & & 3. Loss of autonomy \\
\hline \multirow[t]{2}{*}{ Feeling supported and empowered } & The positive and adaptive outcomes experienced & 1. New and existing models of support \\
\hline & & 2. External change brings relief \\
\hline Feeling separate and isolated & $\begin{array}{l}\text { Explores the alienation from peers, family and support } \\
\text { experienced }\end{array}$ & This major theme had no sub-themes \\
\hline
\end{tabular}

Escalation of Risk

This theme refers to both environmental factors that increase the risk of harm to an individual such as abusive or harmful behaviour, or a lack of oversight and care, as well as the risk of harm that is brought about through increased use of maladaptive coping mechanisms.

Abuse and harmful changes in the home

Increased abuse in the home was relayed by practitioners and associated directly with the impact of lockdown. For example, it was recognised that changed behavioural patterns of parents and adults, such as increased substance abuse, resulted in increased adversity for young people. Practitioners described feelings of confusion and distress. Jennie (F2) shared the experience of one young person who understood the relationship between alcohol and her father's abuse but nonetheless struggled to make sense of how lockdown contributed to an escalation of these behaviours, "What she said was that the sexual abuse increased over lockdown and she wasn't really able to account for why that was. She was aware of the relationship between the abuse and her father's alcohol use. His alcohol use increased over lockdown".

Ellie described the escalation of abuse for one young person which resulted from now spending more time than usual living with an abusive parent, made more intense by that parent now working from home, "they somehow would live with one parent... and then another ...and that was dreadful for them as they had quite an abusive dad, and they were unsure how to cope and relying on friends a lot, and dad was putting them down. He was working from home so they couldn't get away from him." (F2, Ellie). Hence, being homebound escalated risk by reducing a means of escape.

Adopting maladaptive coping mechanisms

In addition to describing external and interpersonal factors that contributed to increased risk and adversity, a number of practitioners highlighted that increasingly young people were talking about maladaptive coping mechanisms such as self-harm or over-exercising alongside increased suicidal thinking. Practitioners recognised that this pattern of thoughts and behaviour had intensified during lockdown, either through increased numbers of young people talking about self-harm or progressing from thinking about self-harm to acting on those thoughts, or through a change in self-harm presentation to more frequent behaviours and changes in method. The effects of isolation and closures of wider services contributed to an increase in self-harm for a young parent who had previously struggled with substance misuse, as described by Anne (F4), "He doesn't know anybody, everything is closed, everything has been shut down for him, so he is self-harming now, that has escalated, when it had previously reduced, it's escalated right up again.". Practical uncertainties around childcare provision with nursery closures, alongside the inability to rely on pre-lockdown support structures, amplified distress for this young person and their perception of inadequacy as a parent. The knock-on effect was increased reliance on self-harm as a coping mechanism.

Similarly, Amy (F3) referred to another young person who described a changing pattern of self-harm behaviour in response to feelings of isolation, "When she first started accessing [the service] and getting support, she didn't really talk about suicidal thoughts or self-harm, ... definitely in recent months I suppose since things have progressed, being in and out of different lockdowns, I definitely noticed an increase in not only suicidal thoughts but now there has been selfharm". 
Practitioners spoke of the devastating implications of removal from sources of potential protection or safeguarding which led to an increase in risk. Some described how it appeared that risk and abuse for young people was given greater reign in the absence of monitoring from a responsible adult or outside agent. This was starkly demonstrated in one case of child sexual exploitation with a young person struggling to cope in the face of an unrelenting new normal, "there was no one having that oversight, she didn't have to be in school, it just became the expectation that she was there for these men every night and it just became beyond anything that she could cope with at all" (F2, Jennie). The young person in this case had been living in care and was moved to live with a family member during the pandemic who they described as having no boundaries. The practitioner's perspective was that this decision, along with the lack of school oversight, permitted the increase in exploitation.

Practitioners described a sense that the increased demand on support services, and lack of service capacity had inevitably led to vulnerable young people being unsupported and let down. They described young people being placed with unsuitable family members, or a feeling that young people were being discharged from a caseload prematurely, as Grace (F3) told us "They had seen her for a few sessions and then got rid of her off their caseload". Added to this, the removal of informal opportunities for someone to step in and monitor or offer support e.g. at school or within the peer-groups, or the reduced capacity of family members who may be dealing with their own mental health difficulties, left individuals in a precarious situation with opportunities for protective oversight reduced, and less access to informal, as well as formal sources of support.

The experience and consequence of loss

This major theme describes the pervasive notion of loss and its consequences, which was notably common to most young people's experiences of lockdown according to practitioners.

The consequences of being physically disconnected

Feeling disconnected from friends unsurprisingly affected lots of young people, with those with both large and small peer groups similarly describing finding it harder to reach out for help and more challenging to cope with difficulties without their friends. Practitioners described the belief of young people that they would be a burden if they were to reach out to their peers or a trusted adult for support and that sense of burdensomeness appeared to be exacerbated by the physical removal from friends, an additional physical as well as mental barrier to reaching out, "she's got a couple of friends she might reach out to but then feels that she might be a burden if she does reach out to them so yeah definitely since spending more time at home it has been harder to reach out" (F3, Amy); "she doesn't want to be a burden on them and because obviously she's not actually seeing people as much, I think it's having a real impact on her" (F3, Grace). Practitioners reflected on how the young people they worked with weren't aware of how important teachers and school had been in their life until they no longer had them. This void was felt keenly - some practitioners felt - for those with little resources at home to fuel hobbies and interests, "they don't cope well without their teachers. School is actually a safe place, especially for the young people who have the more difficult home lives ... you know there isn't money to buy the resources to bake cake every day" (F4, Jackie). Amy (F3) echoed this notion of coming to realise how important physical connectedness had been for young people though it hadn't seemed that way previously, "even though they struggle with friendships, just being around other people has been helpful compared to the situation now'.

Stuck and in Stasis

Practitioners alluded to a sense of 'stasis' whereby an individual's ability to progress with their therapeutic process felt on hold. Young people described feeling physically and emotionally trapped by circumstances which practitioners suggested limited the ability to make therapeutic gains. Zoe (F2), described one young person who lived with a violent partner, with no outlet for relief, "so they were stuck in that place together all the time and there was no outlet for either of them".

Stasis was compounded by the loss of options that processionals could suggest for seeking help whilst restrictions were in place. When writing safety plans, thinking about distraction techniques, or places young people could find community support, practitioners described the void left by the quite sudden removal of protective options. Carly (F1) described one teenage parent she had been working with for a number of months who struggled with bullying and prior to lockdown had been working on building the confidence to go out, "we've worked really hard and they've joined a [fitness] group which is cancelled now. So it's kind of like oh my God, you know, and I think that is going to set them back now a bit, cause you know we have worked for months". For some young people, practitioners described their lives as being 'stuck or 'on hold' and this was seen to contribute to a loss of hope driven by uncertainty around the future and no longer having a clear path that they might have had before the pandemic began, "It was a lot of hope had gone for him as well. The future, what does that look like?" (F2, Zoe).

Loss of autonomy

A dominant experience of loss consistent throughout almost every story we were told related to the notion of a perceived loss of agency and autonomy that young people found frustrating. They described to practitioners a sense of losing choice, losing options, losing places to escape to, and losing the ability to express themselves or make themselves heard. Sharon described a young person living away from home at university, finding themselves in an abusive relationship and feeling unable to make a decision to remove themself from the situation despite wanting to. Sharon (F4) explained, "She's just got that sense of having to stay because the government says I'm not allowed to go back or not allowed to go stay with a friend...you know she often will say, I don't want to be here but even if I want to leave I can't leave, or even if i get to a point where I choose to leave, where am I allowed to go to?". Similarly, Jackie described another young person wanting, but feeling unable to leave a domestic abuse situation at home. She described the layers of fear, guilt, inner conflict and subsequent resignation that emerged for someone who had identified an escape option (an older relative) but could not act upon it. She explained, "they actually needed to get out but they were afraid, they were frightened that if they did..., they couldn't go to their gran's, that would be the place that they would go..., and of course we had this bombardment of 'older people are more susceptible' so they had that guilt, and they couldn't go there" (F4, Jackie).

Loading [MathJax]/jax/output/CommonHTML/jax.js

Page 6/14 
Other instances were described where a change in the family dynamic during lockdown had led to suppression of expression and self-exploration. Ellie described how an overbearing parent repeatedly checking in on their son, had left him with a sense of powerlessness and entrapment. She explained how the balance of control had shifted "he is now being treated on the laptop as a 7-year-old, she checks every message, it's almost like she is trying to stop him ever going forward with his sexuality, again that was because of Covid and the intenseness. What's he doing online with his friends? What's going on? And so every day, that's sort of the problem 'cause mum is over-checking" (F1, Ellie).

Feeling Supported and Empowered

This main theme connects an important pattern of findings which described beneficial and adaptive outcomes that were associated with lockdown, including experiences which demonstrated that individuals benefited from the restrictions.

New and Existing Models of Support

In contrast to accounts of inadequate support and poor outcomes due to overstretched services, for a number of young people there was consistency in support or even an increase in professional provision. Kooth was described as being a consistent place for support that young people could return to weekly and connect with even when other options were no longer available or other structures such as school had been disrupted. Jennie (F1) suggested, "you know she felt that this one hour in the week was such a big part of her routine, just because there is so many gaps in the structure at the time". With Kooth digitally supporting a number of young people with preparing for engagement and readiness for face-to-face services (e.g. CAMHS), there were those for whom the continuation of access to those services was essential for the trust they had spent time developing. The capacity for a continuation of face-to-face support in select other services was very important, "for this young person and a couple of other vulnerable people it felt like it [support] continued and continued in a face-to-face capacity... she was still attending and it felt like a normal support service" (F3, Amy). Inevitably however, new or additional support models, while providing much needed provision, could elicit fears and anxieties for the individuals as a result of change, "he did have more input as well, he got put in touch with a psychologist and they did it online with him and everything so he still had a lot of input going in for him which was great but it was very different so he obviously had to deal with his anxieties with doing it through Zoom" (F2, Jennie).

In addition to formal sources of support, some individuals felt empowered during lockdown to seek support closer to home in a way that they hadn't before. Amy described an individual who had previously struggled to reach out to their foster parents but with limited other options found this to be a useful tool for support and distraction from thoughts of self-harm, "their foster parents are really supportive... if they were having thoughts of harm, that was a distraction for them and they were able to share a bit about what was going on for them...they did start to reach out more, and I think the foster parents were really helpful" (F3, Amy). The circumstances of lockdown helped this individual become aware of the support that existed for them in their home environment, for others this presented as finding innovative ways of coping at home such as organising things in their bedrooms or making comfortable dens to hide out in for a bit.

External change brings relief

Practitioners suggested that many young people welcomed the break from the school environment, especially those who faced peer victimisation, "There were some that loved it [lockdown] 'cause they were no longer being bullied at school and it suited them to be at home, they didn't have to endure pain every day," (F1, Ellie). The relief of not needing to attend school was linked to decreases in self-harm and suicidal ideation for some. However, the temporary nature of school closures, meant the transition back to school was discussed as a cause for anxiety for these individuals, "they then started to get anxiety about going back' (F1, Ellie).

The transition between lockdown and the easing of restrictions served as a catalyst for change for some young people who had used the time to reflect and engage on their situation, becoming empowered to make decisions that had felt too challenging previously. Zoe referenced this when telling us about the young person she worked with, "however hard it was at the very beginning [it] almost gave them strength to change their situation and then when lockdown ended they went out and did something about it. And then one who left her abusive partner and is now living with a family friend in a safer environment" (F2, Zoe). Strength and resilience were the words Zoe used to describe the change that she saw in a couple of the young people she worked with. She suggested that the intensity and challenge of their situations during the first UK lockdown, acted as a catalyst prompting the realisation that change was necessary.

Feeling Separate and Isolated

This theme identifies the pattern of alienation and isolation for those individuals who felt alone in their experiences, unable to relate to their peers, or seek help from their families due to parental difficulties such as financial concern or mental health. The unrelatability extends to feeling as though their experiences of lockdown didn't necessarily match those of others.

Young people from disadvantaged backgrounds and within families experiencing financial hardship often did not feel able to ask for support from their families due to fear of being a burden or creating additional problems and therefore carried a sense of shouldering their worries and concerns on their own. Parents may have been physically or emotionally unavailable, perhaps due to a lack of understanding of their child's concerns, or their own mental health difficulties, which left young people feeling isolated within their home environment, as Amy (F3) described, "So she won't tell her 'oh I'm feeling low, I'm feeling suicidal' as mum might make a joke out of it ... When there are issues in the family with mental health it can be difficult to reach out, I suppose you do get the sense of the isolation a little bit more.".

Experiencing separateness was not new for some of these young people for whom experience with adversity and poor mental health were common, however there were indications that the collective experience of the pandemic (i.e. the narrative of 'we are all in it together') led to harmful comparisons and a heightened feeling of being different which exacerbated feelings of alienation and separation, "Each of my young people see things in a very individual way Loading [MathJax]/jax/output/CommonHTML/jax.js 
perception of how lockdown might look and this is different because of their circumstances" (F4, Jackie). For Barbra, the consequence of the separation experienced by young people manifested in their desperation to be heard and listened to, as if they themselves were in some disbelief about their situation. She described young people saying, "Do you believe me? You believe me?" Really wanting to be believed, and I thought it was really important to be able to be there and tell them that it was not a question of belief, ... but yeah the sense of being alone in this very unsafe world." (F2, Barbra).

\section{Discussion}

We explored the experiences of young people with heightened vulnerability (due to prior experiences, life circumstances and existing mental health difficulties) during the Covid-19 pandemic and national lockdown as understood by mental health professionals working with these groups in a structured or on-going capacity via the web-based platform Kooth. Overall, our findings broadly reflect early indications of a significant impact on the mental health and wellbeing of children and young people during the pandemic and lockdown $(1,5,7)$. Findings point specifically to the contributions of separation and isolation, loss, feeling trapped, and feeling hopeless, which have exacerbated and escalated risk of mental health problems and outcomes such as self-harm, factors already on the rise in young people pre-covid. Importantly, our findings also illustrate resilience and the function of lockdown as a catalyst for change. We offer reflection on the implications of this research for web-based and wider provision of therapeutic support.

\section{Key findings}

A striking but predictable pattern across our data of the experiences of young people during the pandemic and associated lockdowns was the recognition among practitioners that young people who were already vulnerable and at risk of harm were experiencing increased risk both inside and out of the home. This is consistent with data collected early on in the pandemic which described increased risk in relation for example to escalated domestic violence, precarious home environments and other prior experience of ACEs $(14,18,20)$. A contributing factor in the accounts of our practitioners was reduced access to support through the loss of responsible adults and subsequent missed opportunities for care. This resulted in less risk monitoring and detection, and young people feeling unsupported, unnoticed and unsafe. These findings resonate with existing studies (e.g. Donagh, 2020) which have called out the invisibility of young people at risk of domestic abuse during the pandemic. Our findings point to the critical role that schools play not only in the early identification of risk and provision of mental health support, but in providing access to a safe and predictable space and respite away from an abusive or precarious environment, or where young people may experience alienation within the family home. The disruptive impact of school closures on disadvantaged young people for whom consistent attendance at school may have been already challenging, is likely to have significant repercussions beyond the short-term. Of note, while schools have now reopened, the return to school has remained precarious, and evidence indicates that schools are under-resourced to provide the levels of pastoral care and mental health support that many young people may require as we transition out of lockdown. Young people facing additional adversity and inequality are likely to be particularly at risk (3).

Prevalence of self-harm (with and without suicidal intent) in young people has been rising in the years leading up to the pandemic, most sharply in young females (42-44); and while rates of suicide remain lowest in younger age groups (10-24 years) there has been a pattern of increasing suicide in this age group in recent years (45). Despite concerns, to date there is no clear evidence to suggest that rates of self-harm and suicide overall have increased during lockdown and associated restrictions (46) however data is still emerging, and the longer-term impact of the pandemic is uncertain. Evidence does suggest that those with pre-existing mental health diagnoses or with poorer household incomes, have been at greater risk of self-harm and also report higher levels of depression and anxiety (47). Our findings indicate that issues around self-harm and suicide became more common and frequent for young service users since the onset of the pandemic and while we caution against attributing causality to complex patterns of behaviour, the accounts of practitioners are drawn from relationships established with young people prior to the pandemic and maintained over lockdown i.e. they are able to comment on perceived change over the period of interest. Findings also support wider Kooth data from 2020 which showed numbers of children and young people presenting with self-harm had increased by $45 \%$ on the previous year and suicidal thoughts had increased by $40 \%$ accounting for $19 \%$ of all issues on Kooth (12). Factors identified here by practitioners - such as social isolation, feelings of entrapment, and loneliness - are known to contribute significantly to suicide and self-harm risk (48). In addition, practitioners described the sense of young people not wanting to be a burden to others, something exacerbated by the loss of physical closeness. Perceived burdensomeness is a well-documented predictor of suicide (49) emphasised within leading theories of suicide (50) as a critical identifier for suicide prevention. Our findings signal the contribution of enforced physical spacing in contributing to perceived burdensomeness risk which arguably could relate to the perception of increased 'costs' involved for others in providing support remotely, or reduced opportunities through enforced distancing to be reminded that you matter to others.

A narrative over the course of the pandemic has been of society as a whole living through an event which brings individuals together in a collective experience. Such a 'pulling together' effect is referenced in response to other catastrophic global adversities where individuals can feel a sense of togetherness or increased resilience and connection which may act as protective factors, at least in the short term (51). Our findings signal that any sense of shared experience was anathema to vulnerable young people who described feeling more alienated and separate because their experience was so different to the wider societal experience and finding this to be harmful. These individual insights add to existing data evidencing the inequality of experience during the early weeks of lockdown for those with additional and pre-existing adversity $(6,52)$ and demonstrate the need for research and policy approaches which sufficiently take into account the complexity of risk for groups with heightened vulnerability.

Stories of resilience and the individual-led change that occurred for those feeling empowered and supported do suggest that for some vulnerable young people the pandemic has been a critical catalyst for change. Counselling and therapeutic support can be a key element to supporting adaptive coping (23) and the consistent provision of support from Kooth may well have contributed to the capacity for resilience demonstrated by some young people referenced within this study. Previous qualitative work has explored recovery and resilience building following adversity in adolescence, highlighting progress through the ability to take agency and shift perspective (53). Young people spoke of acknowledging, perhaps for the first time, wider systems of support, such as different family

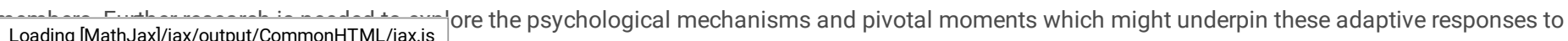


lockdown for young people. We cannot dismiss the experiences that have previously placed these young people into a vulnerable category, nor the ongoing complexity of individual circumstances. These lived experiences will carry trauma and increased possibility of maladaptive coping or adverse life outcomes at a later stage in life $(15,23)$. Longitudinal studies engaging with vulnerable populations following the pandemic are necessary therefore to understand the longer-term impact of lockdown on the relationship between adversity and resilience. Additionally, exploring the contribution of web-based therapeutic support specifically to the maintenance of factors such as increased resilience will be important to investigate.

Implications for support systems

Digital services such as Kooth undoubtedly have an important role to play in providing a stable source of support for young people where care otherwise is unavailable or to support existing provision. Crucially, digital or web-based services which offer anonymity and privacy are seen to provide choice for young people in the support they can seek $(40,54,55)$. This is of particular importance for those who do not feel supported or safe within their home and may not be in a position to engage their parents for support with their mental health, or seek face-to-face support independently. Nonetheless, our findings underscore that digital provision is only one part of a wider support system for young people and make clear the implications for vulnerable young people where access to safe, accessible, ongoing and consistent mental health support provision is removed. The experiences of young service users at Kooth echoed accounts from early on in the pandemic of overstretched services unable to service the level of need $(7,19,27,29)$ and highlighted the sequelae for many service users who began lockdown at greatest risk when wider support needs are unmet. The implications of under-resourced mental health provision were also reported in the frustrations of staff. Practitioners described their experiences as being caught in a 'holding place' alongside the escalation of risk, with limited options for signposting or referring young people for additional support. This left practitioners near burnout and stressed, a critical argument for the importance of integrated services that are equipped to support young people when they need it.

Our findings lend support to calls for a trauma informed approach to ensure the needs of vulnerable young people are safely met (56). A trauma-informed approach involves taking a routine or targeting approach to enquiring about ACEs to create a compassionate and trusting space for support. Health practitioners who trained in trauma-informed enquiry reported feeling more empathetic and understanding of the individuals they came into contact with, especially those who may have previously been considered 'troublesome' (57). The result in using this approach is that young people are more likely to feel heard and achieve better life outcomes. Additionally, using this approach within assessment has been found to support prevention and early intervention due to the earlier disclosure and trust developed through embedding trauma-informed practices (58). In this study practitioners reported sometimes feeling out of their depth with the level of risk they were dealing with. Our findings directly indicate that web-based mental health professionals would benefit from additional trauma-informed training, but also signify that anyone working on the 'front-line' with young people now and in the aftermath of the pandemic - as well as the wider service context in which they work - are likely to benefit from training and support in providing trauma-informed care. This in turn is likely to improve outcomes for young people with ACEs.

Strengths and Limitations of this study

Our focus specifically on the experiences of young people with heightened vulnerability pre-covid is an important strength of the study. Children and young people with increased vulnerability were already at a higher risk of physical, emotional or psychological harm and an increased susceptibility to poorer outcomes in life (16-18) and growing evidence has suggested that those with heightened vulnerability prior to the pandemic have been disproportionately and detrimentally impacted $(7,13,20,47)$. Our qualitative findings provide important additional insight in relation to the experience of lockdown specifically for this group of vulnerable young people. Nonetheless, it is important to note that understanding of the experiences of young people are based on mediated accounts of practitioners and not direct accounts from young service users themselves and this is a limitation of our approach. Our practitioner insights are however based on a continuous service-relationship. That is to say, practitioners were in a privileged position of providing unchanged support for young people from before and during lockdown and were well-placed to identify the impact throughout the time-period of interest. This insight is valuable given that much population-based evidence to date has been drawn from data collected post-pandemic outbreak.

In addition, this approach brings the advantage of understanding the costs and implications of lockdown at a service-level. This study has highlighted the importance of a consistent supportive relationship with a service such as the one that emerges for on-going users of Kooth. At a time when alienation and separation is at the forefront of vulnerable young people's experiences, the ability to be able to explore trust in relationships and experience and sense of belonging and recognition is crucial. Findings have highlighted the need for a trauma-informed approach, currently being rolled out within Kooth, as well as providing further insight to inform the organisation's ongoing suicide prevention strategy.

The participatory involvement of Leaders Unlocked in the study design and analysis is an additional strength and particularly important in the context of the mediated insight approach. The involvement of a diverse group of young people within three participatory workshops provided rigor for example, in introducing valuable critique and reflection on the classification of 'vulnerable' from a youth context. As well as additional validation to support the interpretation of data which was helpful in keeping us aligned with the truth of experience and what matters to young people.

While the dynamic of focus groups completed via video conference interactions benefitted from the small group size, it is recognised that the sample was small and homogenous in terms of gender and ethnicity which may have brought bias to the worldview of practitioners. Participants self-selected to take part and their insights may not be generalisable to other practitioner-service user dyads. Nonetheless, it is noteworthy that the range of professional experience and insight from practitioners aligned well across the focus-groups and introduced new insights for the topic of interest.

\section{Conclusions}

The experiences of young people captured via mental health professionals in this study largely reflect the early findings from the pandemic. It is clear that

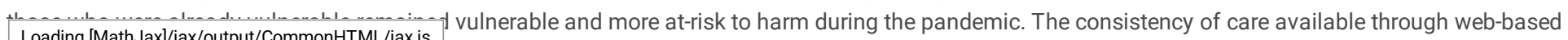


mental health support and the presence of these individuals within that service demonstrates the vital role digital support played and continues to play to prevent young people disappearing from services when world circumstances change in unprecedented ways. There is still a risk that as life returns to 'normal' that vulnerable young people are not met with the support they need at the time they need it, particularly for those who feel alienated. Ongoing research will be required to understand how best to support those who have been most detrimentally affected by the pandemic and what this looks like for the impact across their life course. It is recommended that young people are involved in the design and implementation of this future work.

\section{Declarations}

\section{Ethics approval and consent to participate}

The study was reviewed and approved by the University of Exeter Ethics Committee [eCLESPsy001970]. Consent for participation was collected from all practitioners ahead of their involvement in focus groups.

\section{Consent for publication}

Consent was collected from all practitioner participants for direct quotes to be used and published.

\section{Availability of data and materials}

The datasets analysed during the current study are available from the corresponding author on reasonable request.

\section{Competing interests}

Three of the authors (CM, CO, LS) are employed by Kooth Digital Health where the data for this study was collected. One author (JL) has no competing interests.

\section{Funding}

The PPI and time spent on this study by three of the authors (CM, CO, LS) was funded by Kooth Digital Health. The three Kooth employed authors are researchers by profession and contributed to the design, data collection, analysis and writing of the manuscript.

\section{Authors' contributions}

CM contributed to the design, leading the focus groups, supporting the PPI workshops, analysis of the data from the focus groups, and writing of the manuscript. CO contributed to the recruitment of practitioner participants, supporting the PPI workshops, assisting the focus groups, transcription of the focus group conversations, the analysis of the data, and the writing of the background and methods within the manuscript. LS contributed to the analysis of the data from the focus groups and the writing of the manuscript. JL contributed to the development of the analysis from the focus groups, and made a large contribution to the writing of the manuscript. All authors have read and approved the final manuscript.

\section{Acknowledgements}

We would like to acknowledge Leaders Unlocked and all of the young people who voluntarily took part via Leaders Unlocked in the workshops that enriched the design and interpretation of the findings from this study.

\section{References}

1. Major LE, Eyles A, Machin S. Generation Covid: Emerging work and education inequalities [Internet]. 2020. Available from: https://cep.Ise.ac.uk/pubs/download/cepcovid-19-011.pdf

2. Leavey Cara, Eastaugh Alexandra, Kane Martina. Generation COVID-19 | The Health Foundation [Internet]. 2020. Available from: https://www.health.org.uk/publications/long-reads/generation-covid-19

3. Young Minds. Coronavirus: Impact on young people with mental health needs Autumn 2020. 2020.

4. RCPCH. Our vision - Paediatrics 2040 [Internet]. 2021. Available from: https://paediatrics2040.rcpch.ac.uk/our-vision/

5. Brewer M, Cominetti N, Henehan K, Mccurdy C, Sehmi R, Slaughter H. Jobs, jobs, jobs Evaluating the effects of the current economic crisis on the UK labour market. 2020; Available from: https://www.resolutionfoundation.org/publications/

6. Wright L, Steptoe A, Fancourt D. Are we all in this together? Longitudinal assessment of cumulative adversities by socioeconomic position in the first 3 weeks of lockdown in the UK. J Epidemiol Community Health [Internet]. 2020 Sep 1;74(9):683-8. Available from: http://dx.doi.org/10.1136/jech-2020-214475

7. Romanou E, Belton E. Isolated and struggling: social isolation and the risk of child maltreatment, in lockdown and beyond. 2020.

8. Ford T, John A, Gunnell D. Mental health of children and young people during pandemic Deterioration is clearest among families already struggling 2021;372:n614. Available from: http://dx.doi.org/10.1136/bmj.n614 
9. Panda P, Gupta J, Chowdhury S, Kumar R, Meena A, Madaan P, et al. Psychological and Behavioral Impact of Lockdown and Quarantine Measures for COVID-19 Pandemic on Children, Adolescents and Caregivers: A Systematic Review and Meta-Analysis. J Trop Pediatr [Internet]. 2021 Feb 1;67(1). Available from: https://pubmed.ncbi.nlm.nih.gov/33367907/

10. Brooks SK, Webster RK, Smith LE, Woodland L, Wessely S, Greenberg N, et al. The psychological impact of quarantine and how to reduce it: rapid review of the evidence. Lancet [Internet]. 2020 Mar 14;395(10227):912-20. Available from: http://www.thelancet.com/article/S0140673620304608/fulltext

11. Place2Be. Common worries for young people and families during COVID-19 pandemic [Internet]. 2020. Available from:

https://www.place2be.org.uk/about-us/news-and-blogs/2020/may/common-worries-for-young-people-and-families-during-covid-19-pandemic-survey/

12. Kooth plc. Data Release June 112020 [Internet]. 2020. Available from: https://xenzone.com/wp-content/uploads/2020/06/CYP_Infographic_110620CSE_V5.pdf

13. Jaspal R, Breakwell GM. Socio-economic inequalities in social network, loneliness and mental health during the COVID-19 pandemic: https://doi.org/101177/0020764020976694 [Internet]. 2020 Dec 7; Available from: https://journals.sagepub.com/doi/full/10.1177/0020764020976694

14. Bryant DJ, Oo M, Damian AJ. The rise of adverse childhood experiences during the COVID-19 pandemic. Psychol Trauma Theory, Res Pract Policy [Internet]. 2020;12(S1):S193-4. Available from: /fulltext/2020-43450-001.html

15. Asmussen K, Fischer F, Drayton E, Mcbride T. February 2020 [Internet]. 2020. Available from: https://www.eif.org.uk/report/adverse-childhood-

16. DFE. Working Together to Safeguard Children 2018. 2018.

17. DoH. [ARCHIVED CONTENT] Healthy Child Programme from 5 to 19 years old: Department of Health - Publications [Internet]. 2009. Available from: https://webarchive.nationalarchives.gov.uk/+/http://www.dh.gov.uk/en/Publicationsandstatistics/Publications/PublicationsPolicyAndGuidance/DH_107566

18. NSPCC. Neglect is also Child Abuse: Know All About It | NSPCC [Internet]. 2020. Available from: https://www.nspcc.org.uk/what-is-child-abuse/types-ofabuse/neglect/

19. Young Minds. Prioritising adversity and trauma-informed care for children and young people in England Addressing Adversity. 2020. Available from: www.hee.nhs.uk

20. Stripe N. Domestic abuse during the coronavirus (COVID-19) pandemic, England and Wales - Office for National Statistics [Internet]. 2020. Available from:

https://www.ons.gov.uk/peoplepopulationandcommunity/crimeandjustice/articles/domesticabuseduringthecoronaviruscovid19pandemicenglandandwales/n

21. NYA. Vulnerable Young People: COVID-19 Response Out of Sight? 2020.

22. Donagh B. From Unnoticed to Invisible: The Impact of COVID-19 on Children and Young People Experiencing Domestic Violence and Abuse. Child Abuse Rev [Internet]. 2020 Jul 1;29(4):387-91. Available from: https://onlinelibrary.wiley.com/doi/full/10.1002/car.2649

23. Amnie AG. Emerging themes in coping with lifetime stress and implication for stress management education:

https://doi.org/101177/2050312118782545 [Internet]. 2018 Jun 20;6:205031211878254. Available from:

https://journals.sagepub.com/doi/full/10.1177/2050312118782545

24. Compas BE, Jaser SS, Bettis AH, Watson KH, Gruhn MA, Dunbar JP, et al. Coping, emotion regulation, and psychopathology in childhood and adolescence: A meta-analysis and narrative review. Psychol Bull. 2017 Sep 1;143(9):939-91.

25. Aldao A, Nolen-Hoeksema S, Schweizer S. Emotion-regulation strategies across psychopathology: A meta-analytic review. Clin Psychol Rev [Internet]. 2010 Mar;30(2):217-37. Available from: https://pubmed.ncbi.nlm.nih.gov/20015584/

26. Paul E, Fancourt D. Factors influencing self-harm thoughts and self-harm behaviours over the first 45 weeks of the COVID-19 pandemic in the UK: a longitudinal analysis of 48,446 adults. medRxiv [Internet]. 2021 Feb 22;2021.02.19.21252050. Available from:

https://www.medrxiv.org/content/10.1101/2021.02.19.21252050v1

27. BMA. COVID on our minds - the pandemic has placed even more strain on mental health services [Internet]. 2020. Available from:

https://www.bma.org.uk/news-and-opinion/covid-on-our-minds-the-pandemic-has-placed-even-more-strain-on-mental-health-services

28. Young Minds. Coronavirus: Impact on young people with mental health needs Summer 2020. 2020.

29. Chanchlani Neil, Buchanan Francine, Gill Peter. Addressing the indirect effects of COVID-19 on the health of children and young people. CMAJ [Internet]. 2020;(192):E921-927. Available from: https://www.cmaj.ca/content/cmaj/192/32/E921.full.pdf

30. Young Minds. Coronavirus: Impact on young people with mental health needs March 2020. 2020 Mar.

31. Boydell KM, Hodgins M, Pignatiello A, Teshima J, Edwards H, Willis D. Using Technology to Deliver Mental Health Services to Children and Youth: A Scoping Review. J Can Acad Child Adolesc Psychiatry [Internet]. 2014;23(2):87. Available from: /pmc/articles/PMC4032077/

Loading [MathJax]/jax/output/CommonHTML/jax.js

Page $11 / 14$ 
32. Dhesi M, Sefi A, Donati M, Hayes J, Cooper M. Helpful and unhelpful elements of synchronous text-based therapy: A thematic analysis. Couns Psychother Res [Internet]. 2021; Available from: https://onlinelibrary.wiley.com/doi/full/10.1002/capr.12414

33. McGorry P, Bates T, Birchwood M. Designing youth mental health services for the 21st century: Examples from Australia, Ireland and the UK. Br $\mathrm{J}$ Psychiatry [Internet]. 2018 Jan;202(SUPPL. 54):s30-5. Available from: https://www.cambridge.org/core/journals/the-british-journal-of-

psychiatry/article/designing-youth-mental-health-services-for-the-21st-century-examples-from-australia-ireland-and-theuk/C9090BA043E0ACBDC997C034A38BB4BD

34. Kooth plc. Kooth Pulse 2021 Identifying issues and collaborating to enable positive mental health for all. 2021 Apr.

35. Mawn L, Welsh P, Stain H, Windebank P. Youth Speak: increasing engagement of young people in mental health research. J Ment Health [Internet]. 2015 Sep 3;24(5):271-5. Available from: https://pubmed.ncbi.nlm.nih.gov/26193175/

36. Daley K. The wrongs of protection: Balancing protection and participation in research with marginalised young people: http://dx.doi.org/101177/1440783313482365 [Internet]. 2013 May 8;51(2):121-38. Available from:

https://journals.sagepub.com/doi/full/10.1177/1440783313482365

37. Braun V, Clarke V. Using thematic analysis in psychology. Qual Res Psychol [Internet]. 2006;3(2):77-101. Available from: https://www.tandfonline.com/action/journallnformation?journalCode=uqrp20

38. Braun V, Clarke V. Can I use TA? Should I use TA? Should I not use TA? Comparing reflexive thematic analysis and other pattern-based qualitative analytic approaches. Couns Psychother Res. 2020;(August 2020):37-47.

39. Booth A, Hannes K, Harden A, Noyes J, Harris J, Tong A. COREQ (Consolidated Criteria for Reporting Qualitative Studies). In: Guidelines for Reporting Health Research: A User's Manual [Internet]. John Wiley \& Sons, Ltd; 2014; p. 214-26. Available from:

https://onlinelibrary.wiley.com/doi/full/10.1002/9781118715598.ch21

40. Hanley T, Sefi A, Grauberg J, Prescott J, Etchebarne A. A theory of change for web-based therapy and support services for children and young people: Collaborative qualitative exploration. JMIR Pediatr Parent [Internet]. 2021 Jan 1;4(1):e23193. Available from: https://pediatrics.jmir.org/2021/1/e23193

41. Malterud K, Siersma VD, Guassora AD. Sample Size in Qualitative Interview Studies: Guided by Information Power. http://dx.doi.org/101177/1049732315617444 [Internet]. 2015 Nov 27;26(13):1753-60. Available from:

https://journals.sagepub.com/doi/abs/10.1177/1049732315617444?journalCode=qhra

42. Morgan C, Webb RT, Carr MJ, Kontopantelis E, Green J, Chew-Graham CA, et al. Incidence, clinical management, and mortality risk following self harm among children and adolescents: cohort study in primary care. BMJ [Internet]. 2017 Oct 18;359. Available from: https://www.bmj.com/content/359/bmj.j4351

43. Geulayov G, Kapur N, Turnbull P, Clements C, Waters K, Ness J, et al. Epidemiology and trends in non-fatal self-harm in three centres in England, 20002012: findings from the Multicentre Study of Self-harm in England. BMJ Open [Internet]. 2016 Apr 1;6(4):e010538. Available from:

https://bmjopen.bmj.com/content/6/4/e010538

44. McManus S, Gunnell D, Cooper C, Bebbington PE, Howard LM, Brugha T, et al. Prevalence of non-suicidal self-harm and service contact in England, 2000-14: repeated cross-sectional surveys of the general population. The Lancet Psychiatry [Internet]. 2019 Jul 1;6(7):573-81. Available from: http://dx.doi.org/10.1016/

45. ONS. Suicides in England and Wales - Office for National Statistics [Internet]. 2019. Available from:

https://www.ons.gov.uk/peoplepopulationandcommunity/birthsdeathsandmarriages/deaths/bulletins/suicidesintheunitedkingdom/2019registrations

46. John A, Pirkis J, Gunnell D, Appleby L, Morrissey J. Suicide and the COVID-19 pandemic. Vol. 5, BMJ Editorial. 2020.

47. Iob E, Steptoe A, Fancourt D. Abuse, self-harm and suicidal ideation in the UK during the COVID-19 pandemic. Br J Psychiatry [Internet]. 2020 Oct 1;217(4):543-6. Available from: https://www.cambridge.org/core/journals/the-british-journal-of-psychiatry/article/abuse-selfharm-and-suicidal-ideation-inthe-uk-during-the-covid19-pandemic/692FD08F3AEFF45036535F5E9CEBAA00

48. O'Connor RC, Kirtley OJ. The integrated motivational-volitional model of suicidal behaviour. Philos Trans R Soc B Biol Sci [Internet]. 2018 Sep 5;373(1754). Available from: /pmc/articles/PMC6053985/

49. Hill RM, Pettit JW. Perceived Burdensomeness and Suicide-Related Behaviors in Clinical Samples: Current Evidence and Future Directions. J Clin Psychol [Internet]. 2014 Jul 1;70(7):631-43. Available from: https://onlinelibrary.wiley.com/doi/full/10.1002/jclp.22071

50. Orden KA Van, Witte TK, Cukrowicz KC, Braithwaite S, Selby EA, Joiner TE, et al. The Interpersonal Theory of Suicide. Psychol Rev [Internet]. 2010 Apr;117(2):575. Available from: /pmc/articles/PMC3130348/

51. Zortea TC, Brenna CTA, Joyce M, McClelland H, Tippett M, Tran MM, et al. The impact of infectious disease-related public health emergencies on suicide, suicidal behavior, and suicidal thoughts: A systematic review [Internet]. Crisis. Crisis; 2020. Available from: 
52. Nolan R. 'We are all in this together!' Covid-19 and the lie of solidarity. 2020;29(1):102-6. Available from:

https://journals.sagepub.com/doi/full/10.1177/0791603520940967

53. Shepherd C, Reynolds FA, Moran J. 'They're battle scars, I wear them well': a phenomenological exploration of young women's experiences of building resilience following adversity in adolescence. 2010 Jun ;13(3):273-90. Available from: https://www.tandfonline.com/doi/abs/10.1080/13676260903520886

54. Frith E. Online mental health support for young people. 2017 Nov.

55. Hanley T, Sefi A, Grauberg J, Green L, Prescott J. A positive virtual ecosystem The theory of change for Kooth [Internet]. 2020. Available from: https://explore.kooth.com/wp-content/uploads/2021/02/TOC-2020-report-rebrand_Full-report_digital.pdf

56. Appg. The Covid generation: A mental health pandemic in the making [Internet]. 2021 Apr. Available from: https://publications.parliament.uk/pa/cm/cmallparty/210310/fit-and-healthy-

57. Hardcastle K, Bellis M. Routine enquiry for history of adverse childhood experiences (ACEs) in the adult patient population in a general practice setting: A pathfinder study. Wrexham Public Heal Wales NHS Trust. 2018;

58. Quigg Z, Harrison R, Butler N, Bigland C, Timpson H. Evaluation of a system wide approach to implementing routine enquiry about adversity in childhood (REACh) across Nottinghamshire (Interim report). 2020.

\section{Figures}

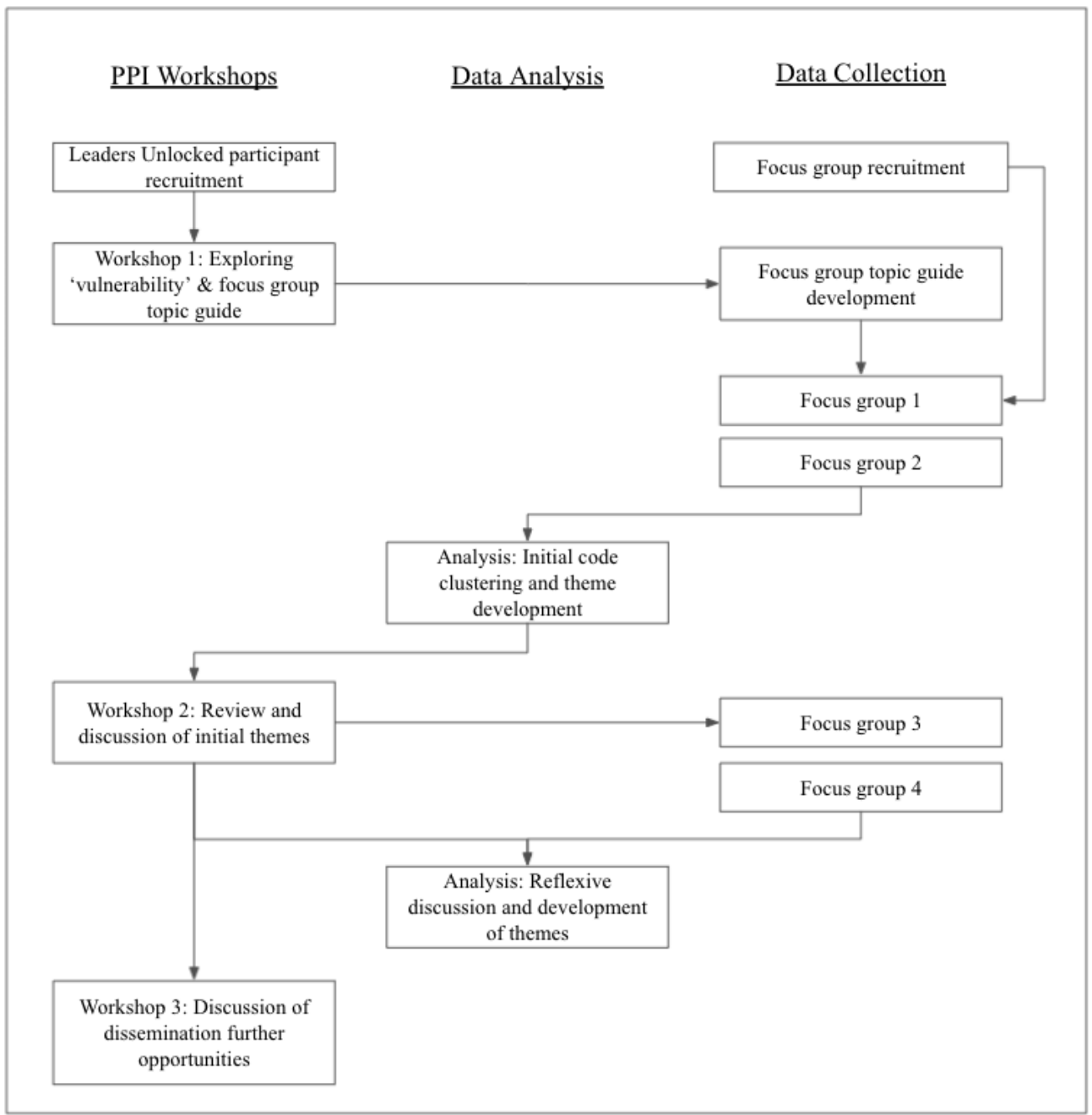

Figure 1

Schematic of Study Design

\section{Supplementary Files}

Loading [MathJax]/jax/output/CommonHTML/jax.js ed with this preprint. Click to download.

Page $13 / 14$ 
- CovidPaperSupplementaryMaterials.docx

Loading [MathJax]/jax/output/CommonHTML/jax.js

Page $14 / 14$ 